\title{
Phylogenetic reconsideration of Myrmekiaphila systematics with a description of the new trapdoor spider species Myrmekiaphila tigris (Araneae, Mygalomorphae, Cyrtaucheniidae, Euctenizinae) from Auburn,Alabama
}

\author{
Jason E. Bond ${ }^{1, \dagger}$, Chris A. Hamilton ${ }^{2, \ddagger}$, Nicole L. Garrison ${ }^{3, \S}$, Charles H. Ray ${ }^{3,1}$ \\ I Auburn University Museum of Natural History, Auburn University, Auburn, AL, 36849, USA \\ † urn:lsid:zoobank.org:author:F5B56990-8D68-4D59-A5C3-07E11FD31661 \\ † urn:lsid:zoobank.org:author:A11AB4EE-74C3-455C-8819-213462B86F2A \\ § urn:lsid:zoobank.org:author:1B165257-BF5C-4FEC-8157-0470DFBF6D2F \\ | urn:lsid:zoobank.org:author:7EBE305E-OB5B-4CE2-8784-A4F30C9D1F5A \\ Corresponding author: Jason E. Bond (jbond@auburn.edu)
}

Academic editor: M. Kuntner | Received 25 February 2012 | Accepted 25 April 2012 | Published 4 May 2012

urn:lsid:zoobank.org:pub:F6500AE5-B3F1-4DF3-9A11-B9B74D386B06

Citation: Bond JE, Hamilton CA, Garrison NL, Ray CH (2012) Phylogenetic reconsideration of Myrmekiaphila systematics with a description of the new trapdoor spider species Myrmekiaphila tigris (Araneae, Mygalomorphae, Cyrtaucheniidae, Euctenizinae) from Auburn, Alabama. ZooKeys 190: 95-109. doi: 10.3897/zookeys.190.3011

\begin{abstract}
The trapdoor spider genus Myrmekiaphila currently comprises 11 nominal species. A recent molecular phylogenetic evaluation of the group identified a number of problems with respect to how species and species groups were delineated by Bond and Platnick in their 2007 taxonomic revision of the genus. We report herein the discovery of a new species, Myrmekiaphila tigris sp. n. The phylogenetic position of the species is evaluated using a molecular phylogenetic approach based on a set of mtDNA markers. Our preferred phylogenetic hypothesis supports the recognition of a new species and further highlights the need to more carefully investigate species boundaries within the genus. These results further indicate that palpal bulb morphology is rapidly evolving and has likely been a contributing factor in rendering a number of species paraphyletic with respect to the molecular data.
\end{abstract}

\section{Keywords}

New species, Integrative taxonomy, Molecular taxonomy, Southeastern United States, Myrmekiaphila, Cyrtaucheniidae, Euctenizinae

Copyright Jason E. Bond et al. This is an open access article distributed under the terms of the Creative Commons Attribution License 3.0 (CC-BY), which permits unrestricted use, distribution, and reproduction in any medium, provided the original author and source are credited. 


\section{Introduction}

The genus Myrmekiaphila Atkinson, 1886 is a moderately diverse assemblage of trapdoor spiders distributed predominantly throughout the southeastern United States. Revised recently by Bond and Platnick (2007), it presently comprises 11 nominal species that range from Virginia southward to the Gulf Coast and extending as far west as central Texas. All known Myrmekiaphila species construct a silk-lined burrow, covered by a silken-soil trapdoor, from which they forage as sit and wait predators; many burrows are uniquely modified to include a side chamber that can be closed from the main chamber by a second trapdoor. As discussed by Bond and Platnick (2007) the familial placement of the genus has been somewhat problematic, however, molecular studies of mygalomorph phylogeny (Bond and Hedin 2006, Hedin and Bond 2006, and Bond et al. in review) place the genus in what is now recognized as the North American cyrtaucheniid subfamily Euctenizinae, to be elevated to family rank (Bond et al. in review).

Myrmekiaphila species delimitation and diagnosis relies heavily on modifications of the male first walking leg - often termed the mating clasper - and the morphology of the palpal bulb. Mating clasper morphology is typically discriminated on the basis of unique spination patterns whereas palpal bulb modifications are often quite dramatic comprising relatively pronounced branched and serrated structures (Fig. 1). Such major differences in palpal bulb morphology stand in relatively stark contrast to the paucity of differentiation observed for palpal bulb structure in other related mygalomorph taxa (see Bond 2004, Stockman and Bond 2008). Despite the disparities in male morphology, female specimens are relatively homogenous with only subtle differences in spermathecae morphology rendering them nearly impossible to identify without the aid of molecular markers. Consequently, Bond and Platnick (2007) provided a morphological key only for male specimens.

On the basis of palpal differences, presence or absence of a second prong and serration patterns (Fig. 1 but also see Bailey et al. 2010, Figure 1), Bond and Platnick (2007) divided the genus into three species groups; they acknowledged at the time that these groupings were without phylogenetic support. A subsequent molecular based study of Myrmekiaphila species relationships by Bailey et al. (2010) indeed demonstrated these species groups were not monophyletic. Most notably the results of their analysis indicated that Myrmekiaphila torreya Gertsch \& Wallace, 1936, a species with a dual pronged bulb, is paraphyletic with respect to M. coreyi Bond \& Platnick, 2007, a species with a single prong and diminutive serration. Consequently, the species "tree" (i.e., prior hypothesis of species boundaries) was in conflict with the gene tree. Bailey et al. (2010) hypothesized that palpal bulb evolution appeared to be quickly outpacing the evolutionary patterns conveyed by the mitochondrial and nuclear markers (incomplete lineage sorting) used to infer phylogeny and that it was unlikely that the putative $M$. torreya lineages harbored cryptic diversity because of a general lack of geographical concordance among its lineages. This paper documents the discovery of a new Myrmekiaphila species that brings into question the hypothesis that incomplete lineage is the cause of the observed gene-tree species-tree incongruence. Rather, the study system may suffer from 


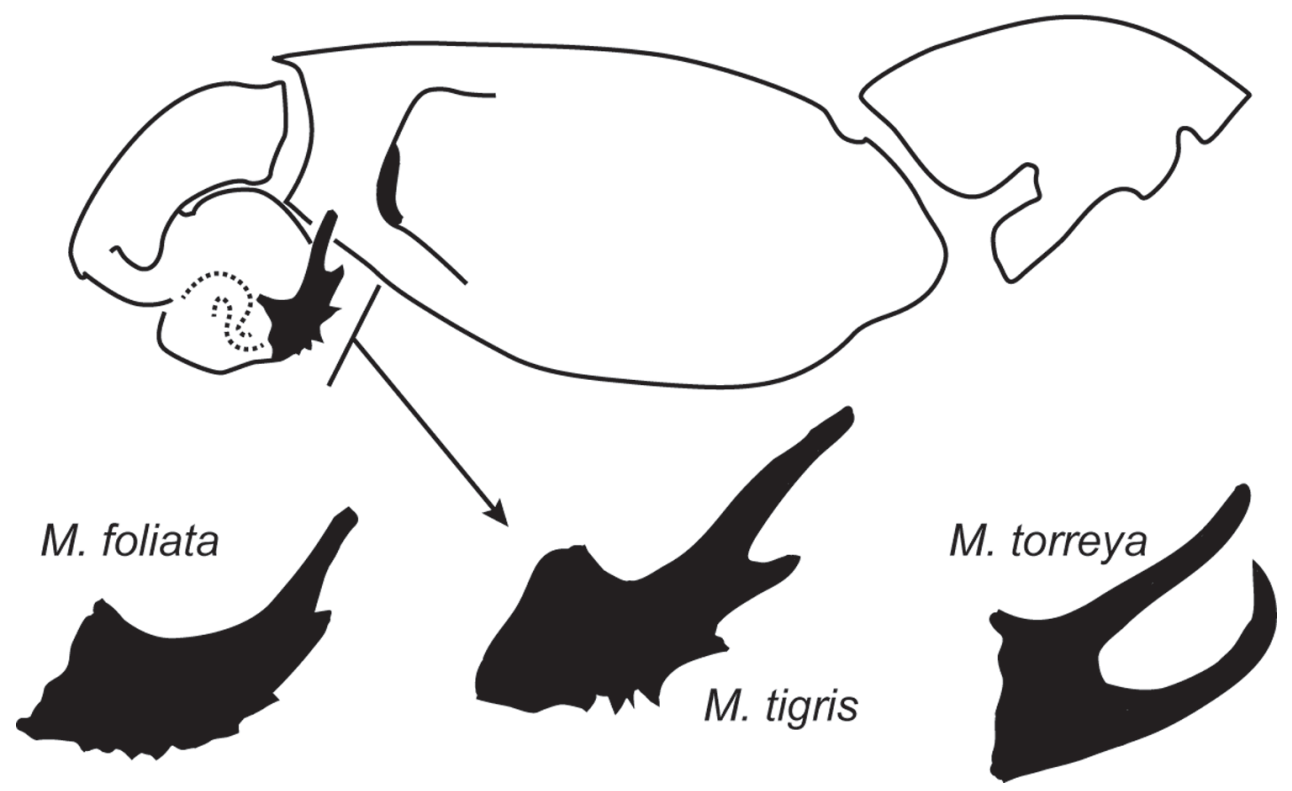

Figure I. Line drawing of Myrmekiaphila tigris male pedipalp; distal aspect of palpal bulb shown for $M$. foliata, M. tigris, and M. torreya for comparative purposes.

"bad taxonomy" (see Funk and Omland 2003). That is, that Bond and Platnick (2007) may have overlooked some of the morphological diversity contained within the group.

The focus of this paper is the description of a new species, Myrmekiaphila tigris Bond \& Ray. This species was brought to the attention of the first author by C. Ray who collected numerous specimens during the winter months (Dec-Jan) of 2011/2012 from sidewalks and swimming pools located in the town of Auburn, Alabama in a moderately populated housing subdivision. Bond and Platnick (2007) had examined specimens from the vicinity of the type locality reported herein, but seemingly misidentified them as Myrmekiaphila foliata Atkinson, 1886. Examination of the newly acquired specimens and reexamination of the earlier collected material found these specimens to bear some likeness to $M$. foliata but upon close inspection, notable differences in the palpal structure (discussed in the diagnosis of the species below) came to light. That said, given the putative widespread distribution of $M$. foliata it would not be unreasonable to infer that the variation noted in these specimens simply represents a geographic variant of the species and thus recognition of new species is not necessarily warranted (i.e., if we ignore the fact that mygalomorph taxa are prone to species crypsis; see Bond and Stockman 2008). As such, it seemed prudent to consider an independent assessment of the hypothesized new taxon using molecular data before proposing a new name. The study reported here provides molecular evidence that warrants recognition of a new species, further documents the somewhat complicated relationships of species contained within the genus, and formally describes this newly recognized lineage as a nominal species. 


\section{Materials and methods}

Unique voucher numbers were assigned to all specimens (AUMS) and corresponding labels added to each vial. Collecting locality latitude/longitude data was georeferenced as described in Bond and Platnick (2007); georeferenced specimens from older museum labels given in brackets [ ] in the material examined section of the species description. All measurements were taken with a Leica MZ16.5 stereomicroscope equipped with a 10X ocular and ocular micrometer scale. Measurements were taken from the left appendage, usually in retrolateral view, using the highest magnification possible. Leg article measurements were taken as described in Bond and Platnick (2007). Illustrations were prepared using a Visionary Digital Imaging System (Ashland, VA). Photographs were recorded in multiple focal planes and assembled using the Zerene Stacker software package (Zerene Systems LLC, Richland, WA). Carapace and leg coloration are described using Munsell Soil Color Charts (Windsor, NY) and are given using the color name and hue value/chroma notation.

Species descriptions are formatted similarly to Bond (2004) and Bond and Platnick (2007) for consistency and comparative purposes. Institutional abbreviations: AMNH - American Museum of Natural History; CAU and AUMNH - Auburn University Museum of Natural History; CDF - personal collection of D. Folkerts, deposited in AUMNH; FMNH - Field Museum of Natural History. Morphological abbreviations: $\mathrm{Cl} / \mathrm{w}$ (carapace length/width), STRl/w (sternum length/width), LBl/w (labium length/ width), A/PER (anterior/posterior eye row), A/PME (anterior/posterior median eye), $\mathrm{TSp} / \mathrm{r}$ and TSrd (male tibia I spines prolateral/retrolateral and retrolateral distal), PTw/l (male palpal tibia width/length), Bl (palpal bulb length), PT/TB3s (female patella/ tibia III spines). Leg I article measurements are in the following order: femur, tibia, metatarsus, and tarsus; leg IV measurements are femur and tarsus only.

Protocols for sample, tissue, DNA extraction, polymerase chain reaction (PCR), and sequencing follow those outlined in Hendrixson and Bond (2007) and Bailey et al. (2010). Using those procedures we amplified for five exemplar specimens the $12 \mathrm{~S} / 16 \mathrm{~S}$ mitochondrial DNA region using the PCR primers LR-J-12887 and SR-N-14612 (Simon et al. 1994). This mtDNA region was used by Bailey et al. (2010) in combination with a nuclear coding protein gene that showed a largely congruent phylogenetic pattern. Paratype specimens AUMS077, 089, 119 comprised a male and two female specimens collected from the type locality; AUMS095 is from a locality in the region, Tuskegee State Park. Specimen AUMS078 is a putative M. torreya Gertsch \& Wallace, 1936 juvenile specimen from the proximity of the M. tigris type locality (outskirts of Auburn, AL, Lee County). The resulting fragment was sequenced using the PCR amplification primers plus an additional internal primer, SR-N-13xxxa (Bond and Stockman 2008). The fragments were assembled and edited using the computer program Geneious Pro v5.5.4 (Auckland, New Zealand). The final edited sequences (Genbank accession numbers JQ708211- JQ708215) were added to the existing Myrmekiaphila 12S/16S data matrix (Treebase accession S10740) and aligned to the existing alignment using the pairwise alignment tool in Mesquite (Maddison and Maddison 2009). Data partitions and model choice for Bayesian phylogenetic inference is outlined in Bailey et al. (2010). 
Tree searches on the partitioned data set using Maximum Likelihood and Bayesian inference were conducted using RAxML ver. 7.2.8 (Stamatakis 2006) and MrBayes ver 3.1.2 (Huelsenbeck and Ronquist 2001; Ronquist and Huelsenbeck 2003), respectively. RAxML analyses comprised 1,000 random sequence addition replicates (RAS) using the commands “-\# 1000" and "-m GTRGAMMA". Bootstrap support values were calculated using the same search parameters with 1,000 replicates. Results from the bootstrap analysis were then applied to the best tree recovered from the RAS search. The MrBayes tree search comprised two independent runs of four simultaneous Markov Chain Monte Carlo (MCMC) chains. The Bayesian analyses were run for 20,000,000 generations with trees sampled every 1,000 generations; the first 25\% were discarded as burn-in. Likelihood values for all post-analysis trees and parameters were evaluated for convergence and burn-in using the "sump" command in MrBayes and the computer program Tracer ver. 1.5 (Rambaut and Drummond; http://evolve.zoo.ox.ac.uk/software.html?id=tracer). Trees remaining after burn-in were used to calculate posterior probabilities using the "sumt" command.

\section{Data resources}

Phylogenetic data sets (NEXUS and PHYLIP format) for all specimens evaluated in this study; locality data for Myrmekiaphila tigris.

The data underpinning the analysis reported in this paper were deposited on 25 April 2012 in the Dryad Data Repository at doi: 10.5061/dryad.pk24v (Bond et al. 2012) and at GBIF, the Global Biodiversity Information Facility, http://ipt.pensoft. net/ipt/resource.do?r=myr_dataset.

\section{Results and discussion}

The - In likelihood value for the best scoring tree recovered from the RAxML analysis was $-11,248.44$. The harmonic and arithmetic means of the log likelihood values for all post burn-in topologies following MrBayes analyses were $-11,307.70$ and $-11,364.56$, respectively. Figure 2 summarizes the results of the phylogenetic analysis. The trees inferred from the both the Bayesian and likelihood analyses were largely congruent with respect to tree topology; bootstrap support values were less than posterior probabilities at some nodes.

The inferred phylogeny clearly indicates the hypothesized new species is not closely related to $M$. foliata and is placed within the somewhat enigmatic torreya species group (sensu Bailey et al. 2010). Although its exact placement within the group as sister to a clade that includes both taxa with unbranched ( $M$. coreyi) and branched ( $M$. torreya, sensu lato) emboli lacks strong nodal support, its placement among taxa with divergent morphologies is strongly supported and unequivocal with respect to these data. Given the distinctiveness of the M. tigris palpal bulb (Fig. 1), it would be impossible to confuse the new species with other members of the torreya clade. And, these specimens clearly do not share common ancestry with $M$. foliata, thus do not represent a distinct 


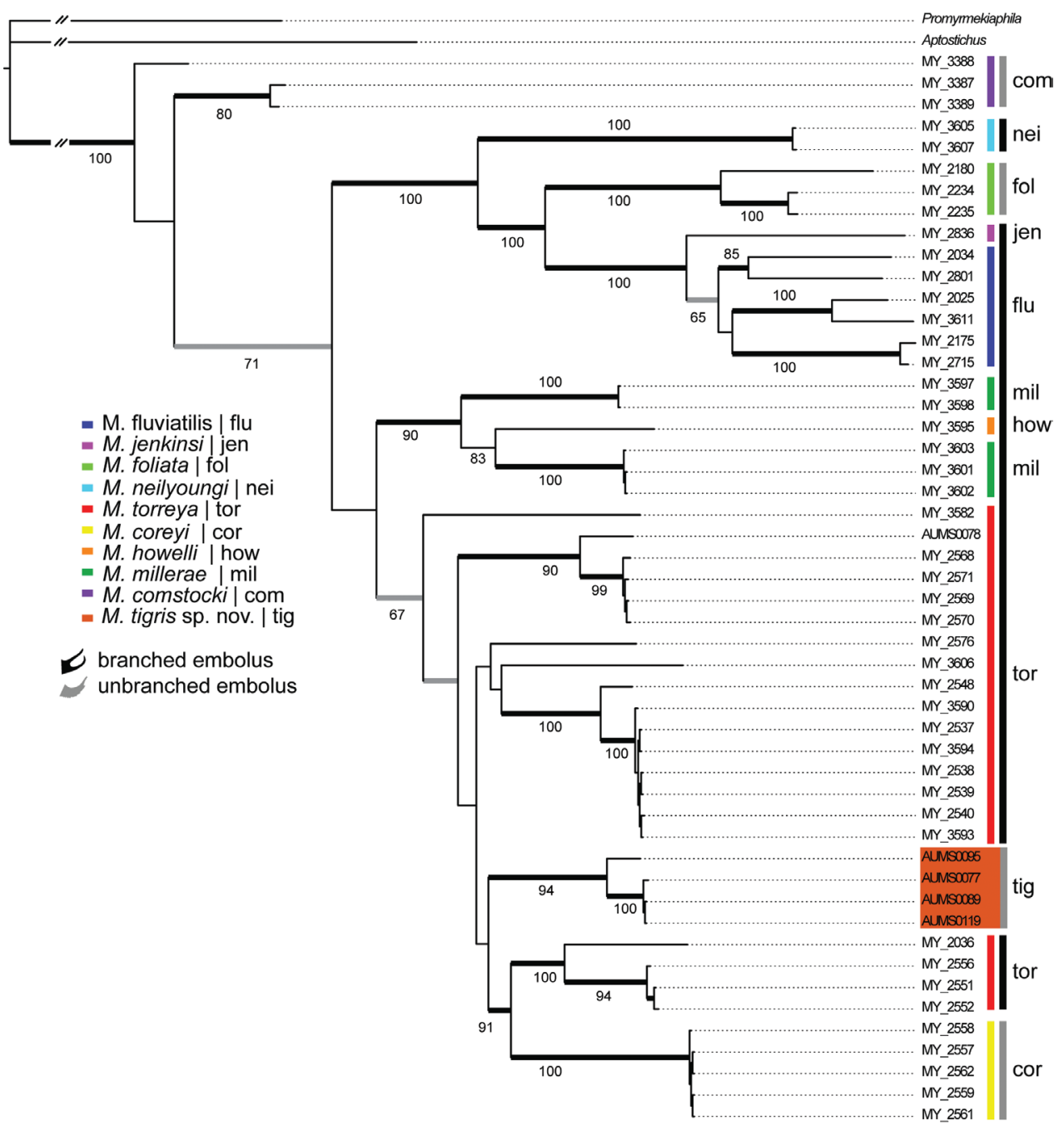

Figure 2. Preferred tree topology based on Bayesian analysis of the $12 S / 16 S$ mitochondrial DNA data set. Color key and three-letter identifiers (inset) refer to species defined by Bond and Platnick 2007 along with the new species, $M$. tigris, described in this study and palpal bulb condition (one-pronged vs. two-pronged). Thickened black branches indicated posterior probabilities $>0.95$; gray branches denote values of $0.90-0.95$. Numbers at nodes are bootstrap percentages from the maximum likelihood analysis conducted in RAxML.

geographic variant of that species. Based on these molecular data coupled with the distinctive, easily diagnosable morphology (Fig. 1), the recognition of a new species is clearly warranted. As discussed in the Taxonomy section below, specimens incorrectly identified as M. foliata by Bond and Platnick (2007) are in need of reexamination.

The discovery of a second species with an unbranched embolus phylogenetically "embedded" within the torreya species group further complicates the systematics of the genus and generates more questions regarding species delimitation and the nature of the 
evolution of these somewhat enigmatic palpal bulb modifications. As discussed by Bailey et al. (2010), $M$. torreya remains a paraphyletic species with respect to $M$. coreyi, and now $M$. tigris. Solutions to resolving the conflict between the gene tree and the taxonomy of this species group include recognizing all "basal" lineages as species (speciation by remote control sensu Templeton 1998) or collapsing the entire clade into a single species. Given the degree of morphological divergence contained within the lineage (sensu lato), considering the entire clade as one species is not sufficient and would overlook significant diversity. Alternatively, recognizing all of the lineages within the torreya group as species seems premature. First, as hypothesized by Bailey et al. (2010) M. torreya paraphyly may simply reflect the rate at which genitalic change has occurred within the group as a consequence of sexual selection by female choice or sexual conflict thereby resulting in incomplete lineage sorting in the mtDNA data. The phylogeographic pattern reported here also fits with the hypothesis discussed by Bailey et al. (2010) that branched and unbranched palpal bulb conditions always occur where congeners are sympatric. Indeed, the phylogenetic position of specimen AUMS0078 (Auburn, AL, putative M. torreya specimen) seems to suggest that $M$. torreya and $M$. tigris may be sympatric. However, the full extent and potential overlap of both species has not yet been thoroughly investigated. Nevertheless it does seem plausible that genitalic evolution by selection and/or as a consequence of classical character displacement could be outpacing the rate of molecular divergence. However, that hypothesis may continue to breakdown as specimens are more closely examined in light of the molecular data. The discovery of a new species coupled with the phylogenetic hypothesis further magnifies the complexities contained with the genus and may indicate that the lineages contained within the torreya clade be considered as five species. As such it seems clear that considerable work remains in terms of sampling more extensively (i.e. geographical, morphological, and molecular data); we simply lack sufficient data to properly delineate all of the species at this time. Consequently, considerable work remains if we are to gain an understanding of species boundaries and genitalic evolution within this interesting group of trapdoor spiders.

\section{Taxonomy}

\section{Myrmekiaphila tigris Bond \& Ray, sp. n.}

urn:lsid:zoobank.org:act:1879EB33-3133-4A1A-96E5-5C2176A1AFB7

http://species-id.net/wiki/Myrmekiaphila_tigris

Common name: The Auburn Tiger Trapdoor Spider

Map 1; Figs 3-11

Myrmekiaphila foliata Atkinson, 1886 (misidentification): Bond and Platnick, 2007: 9-10.

Type material. Male holotype (AUMS090), female paratype (AUMS089, from Alabama, Lee County, Auburn, along Grove Hill Road, forested area across from intersec- 


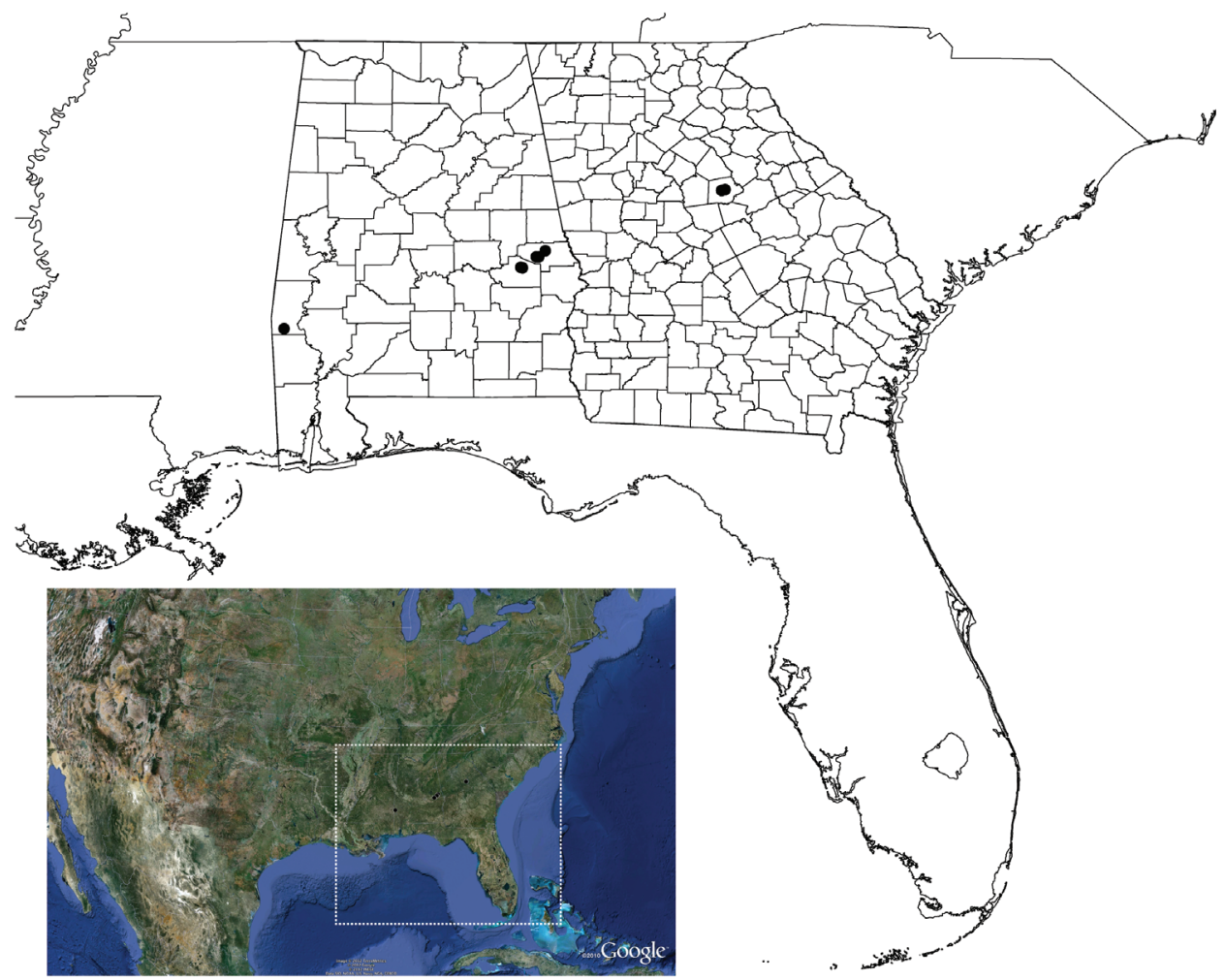

Map I. Geographic distribution of Myrmekiaphila tigris. County outlines for Alabama and Georgia are shown. Lower color inset, dotted line, shows extent of distribution map.

tion with High Point Drive, 32.5786, -85.4543, 180m, coll. J. Bond 25.i.2012; additional male paratypes (AUMS077, 081-084) from same vicinity, coll. C. Ray i.2012. Male holotype and female paratype deposited in AUMNH; additional male paratypes deposited in AUMNH, AMNH and FMNH.

Additional material examined. ALABAMA: Choctaw Co.: Silas [31.7654, -88.3290, MYR013], 19.ii.1912 (H. Smith, CUC), 1 ð. Lee Co.: Opelika [32.6454. -85.3783, MYR133], 1.i.1985 (D. Folkerts, CDF), 1ðß; 3.2km S Auburn along Wire Road [32.5776, -85.5246, MYR135], 24.ii.1974 (R. Skinner, CAU), 10; Auburn [32.6099, -85.4808, MYR124], (AMNH), 2q, 1 juv., [MYR127], (N. Banks, C. Baker, MCZ), 1ㅇ, [MYR132], 10.iv.1941 (AMNH), 3ㅇ, [MYR137], 3.iii.1968 (W. Ivey, CAU), 10, [MYR139], 10.v.1975 (B. Muse, CAU), 19, [MYR288], 1.vi.1986 (G. Mullen, CAU), 19; Auburn, Grove Hill subdivision, 32.5786, -85.4543 (AUMS086-088, 091, 096-115, 117-119, 121, 123-127, 130-138), 180m, xii.2011-i.2012 (C. Ray, D. Held, J. Bond, N. Garrison, AUMNH), 41^ 2 ㅇ, 5 juv. Macon Co.: Tuskegee National Forest, Wire Road, S Interstate 85 [32.4577, -85.6576, MYR138], 12.xii.1975 (Weatherby, Brooks, CAU), 1 9 ; Tuskegee National Forest, 32.4522, -85.6378 [AUMS094-095], 30.i.2012 (C. Hamilton, AUMNH), 


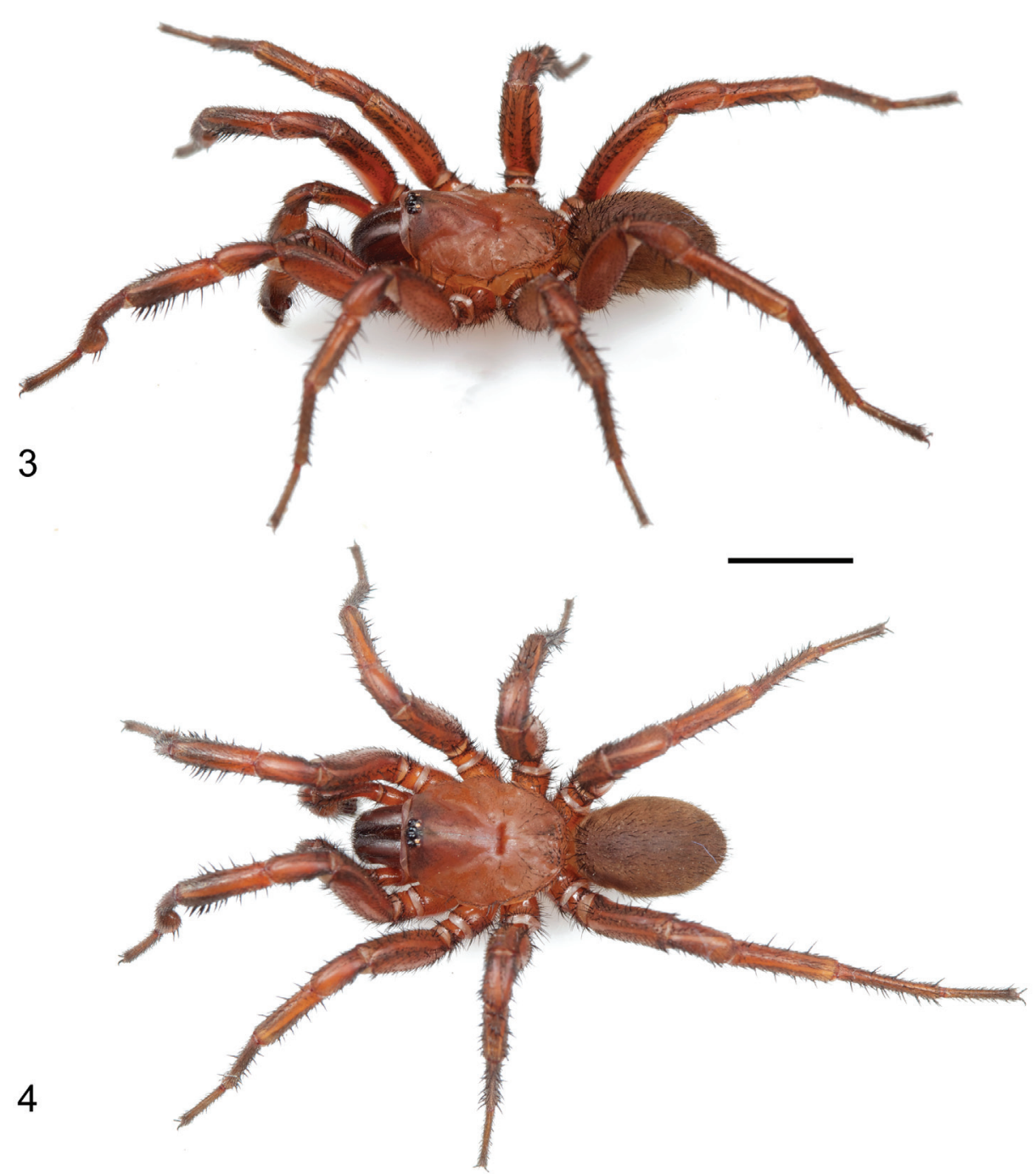

Figures 3, 4. Myrmekiaphila tigris sp. n. male holotype specimen in life. 3 oblique view $\mathbf{4}$ dorsal view. Scale bar $=5 \mathrm{~mm}$.

2 juv. Montgomery Co.: McGus Station [MYR140], 24.x.1915 (H. Smith, CUC), 10. GEORGIA: Putnam Co.: no specific locality [33.3335, -83.3499, MYR040], 23.iv.1974 (W. Merrill, FSCA) 1ô; Eatonton [33.3268, -83.3885, MYR131], 18.iv.1974 (W. Merrill, FSCA), 10 ก.

Etymology. The specific epithet, the Latin name for tiger, is a noun taken in apposition and refers to the mascot of Auburn University.

Diagnosis. Male palpal bulb morphology (Figs 7, 8) is similar to M. foliata (Fig. 1 , inset) but $M$. tigris specimens have a longer sinuous embolus with an elongate sub distal tooth. Potentially sympatric $M$. torreya males have two-pronged bulb whereas $M$. 


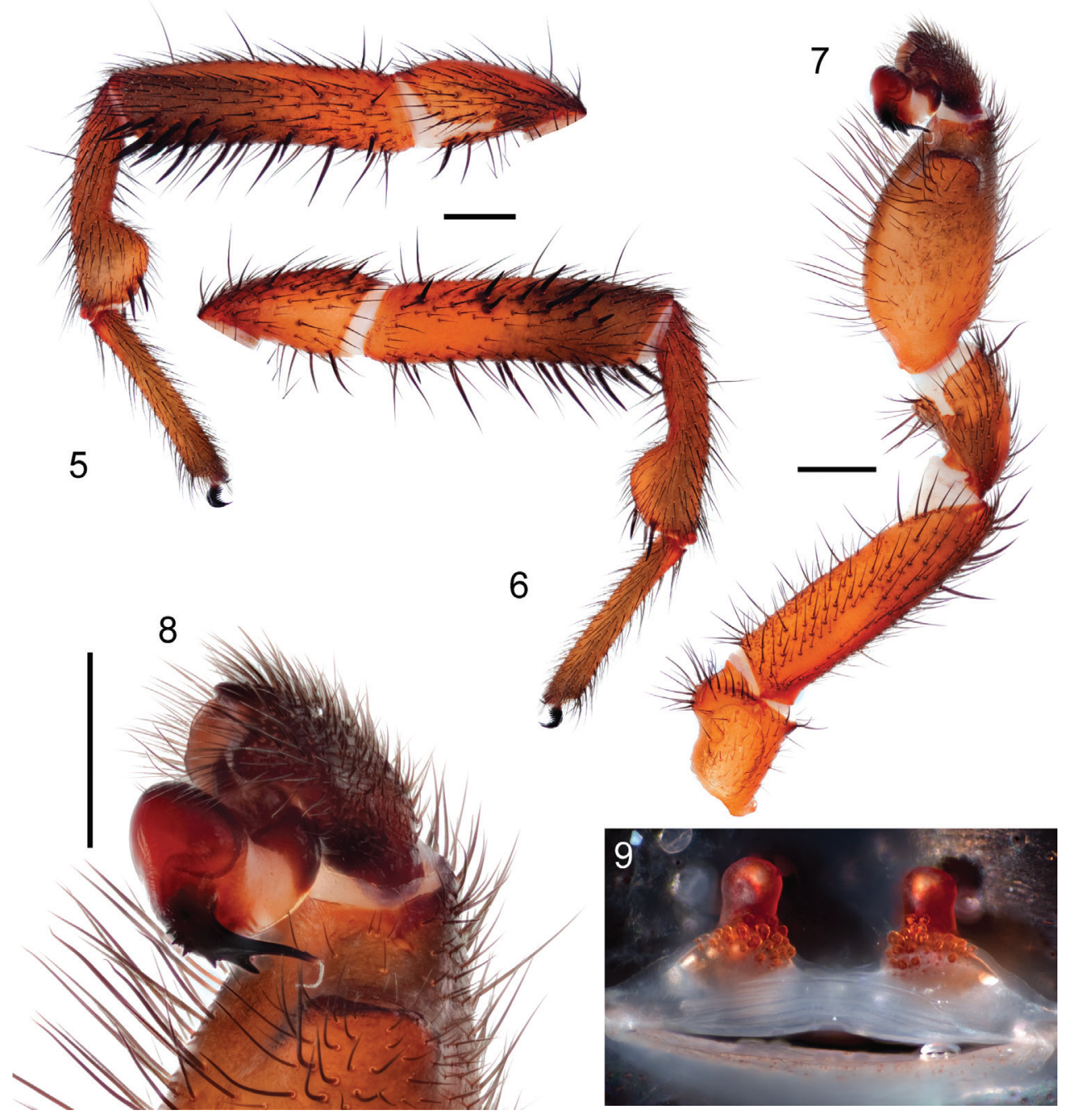

Figures 5-9. Myrmekiaphila tigris sp. n. male holotype and female paratype. 5, $61^{\text {st }}$ walking leg of male, left side retrolateral and prolateral view $\mathbf{7}$ pedipalp, retrolateral view $\mathbf{8}$ palpal bulb $\mathbf{9}$ cleared spermathecae. Scale bars $=1 \mathrm{~mm}$.

tigris males have only a single prong. Males also appear to have a more robust palpal tibia with a larger retro-distal lateral ledge than in other species (Fig. 7). Females are much more difficult to definitively recognize from other species on the basis of morphological differences, however, the spermathecal base is considerably less wide than noted for M. torreya (Bond and Platnick 2007) and central bulb has a more elongate stalk (Fig. 9). Also, male and female $M$. tigris specimens tend to be larger in size than recorded for closely related $M$. coreyi: $M$. tigris $\mathrm{Cl}$ male $>6.50$, female 7.36; $M$. coreyi $\mathrm{Cl}$ male $<4.50$, female $<6.00$. Specimens are phylogenetically distinct as a monophyl- 

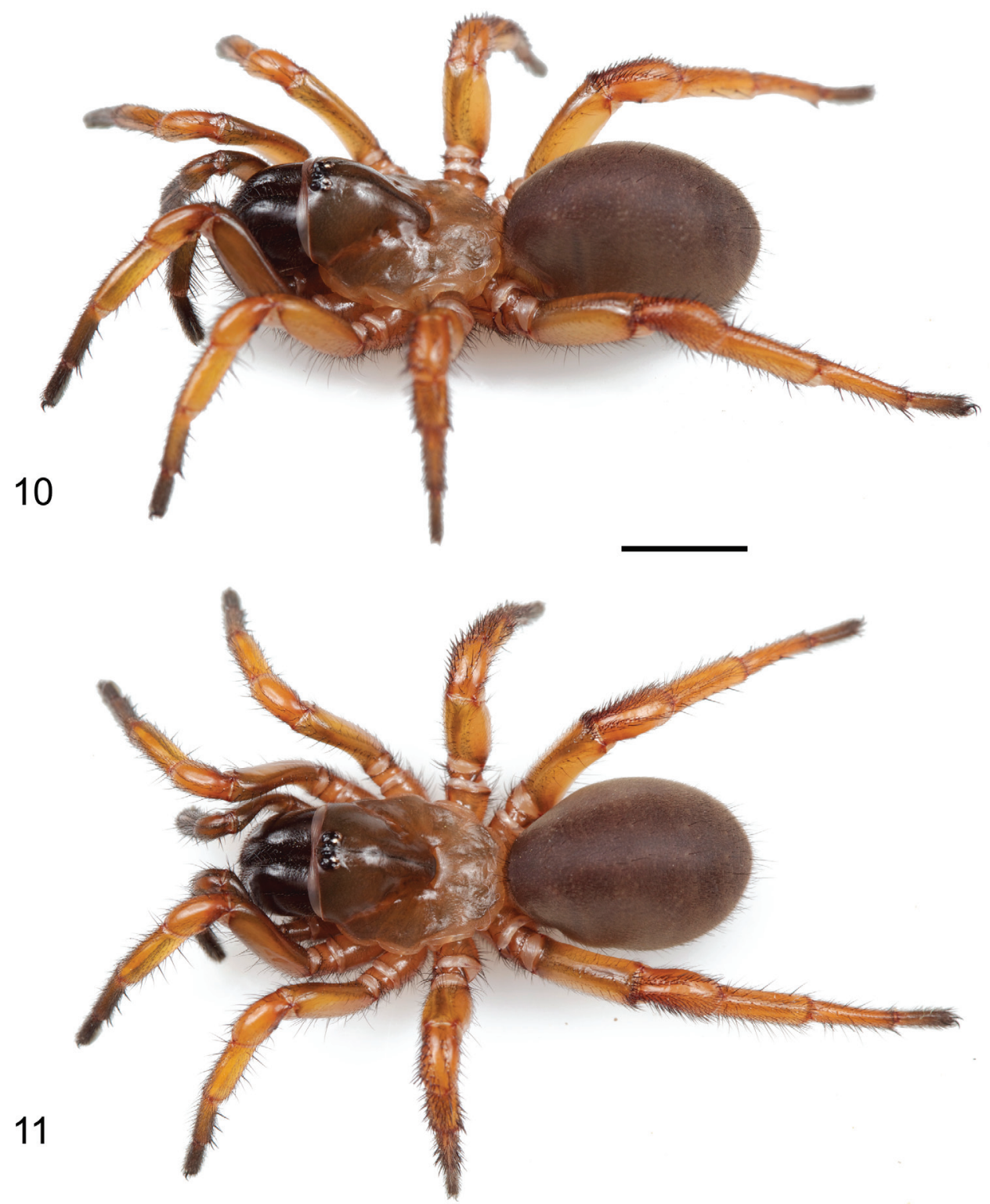

Figures I 0, I I. Myrmekiaphila tigris sp. n. female paratype specimen in life. I 0 oblique view I I dorsal view. Scale bar $=5 \mathrm{~mm}$.

etic lineage exclusive of $M$. torreya, M. coreyi, and $M$. foliata (Fig. 2). Known only from central Alabama and Georgia.

Description of male holotype. Specimen preparation and condition. Specimen collected live from burrow, preserved in $80 \%$. Pedipalp, leg I left side removed, stored in vial with specimen. General coloration. Carapace dark red 2.5YR 3/6; legs, chelicerae 
darker in color, dusky red 10R 3/4. Abdomen dark brown 7.5YR 3/2 with broad faint dusky stripes posteriorly dorsal (Figs 3, 4), ventrum spinnerets pale yellow. Cephalothorax. Carapace 6.56 long, 5.63 wide, hirsute with thin black short setae, stout black bristles along fringe; surface smooth, pars cephalica elevated. Fringe, posterior margin with black bristles. Foveal groove deep, straight. Eyes only slight elevated. AER slightly procurved, PER slightly recurved. PME slightly larger in diameter than AME. Sternum moderately setose, STRl 3.72, STRw 3.35. Posterior sternal sigilla large, irregularly shaped, nearly contiguous, anterior sigilla pairs small, oval, marginal. Chelicerae with distinct anterior tooth row comprising 11 teeth, posterior margin with single row small denticles. Palpal endites with patch of small cuspules on proximal, inner margin, labium lacks cuspules, LBw 1.19, LBl 0.70. Rastellum consists of 4 stout spines on distinct mound. Abdomen. Setose, heavy black setae intermingled with fine black setae. Legs. Leg I: 5.85, 2.88, 4.25, 3.41, 2.84; leg IV: 6.00, 3.25. Light scopulae on tarsi, metatarsi legs I, II. Tarsus I with single, slightly staggered row of 9 trichobothria. Leg I spination pattern illustrated in Figures 4, 5; TSp 12, TSr 10, TSrd 2. Pedipalp. Articles stout, lacking distinct spines (figs 6, 7). PTw 1.50, PTl 3.00, Bl 1.24. Distinct, elongate ledge on distal-retrolateral aspect tibia. Embolus stout, tapering sharply towards tip, with serrations, elongate distal tooth (Fig. 8).

Variation (8). Cl 6.81-10.30, 7.56 $\pm 0.41 ; \mathrm{Cw} 5.40-8.08,6.08 \pm 0.30$; STRl $3.80-5.25,4.14 \pm 0.17$; STRw 3.38-4.85, 3.71 \pm 0.17 ; LBw 1.02-1.57, 1.21 \pm 0.07 ; LBl 0.56-0.70, 0.64 \pm 0.02 ; leg I: $5.35-8.32,6.29 \pm 0.31 ; 4.60-5.75,4.73 \pm 0.16 ; 3.25-$ 4.85 , 3.75 $\pm 0.18 ; 2.88-4.20$, 3.14 \pm 0.16 ; leg IV: 5.75-8.88, 6.52 $\pm 0.35 ; 3.09-4.45$, 3.48 \pm 0.16 ; PTl 3.00-4.32, 3.27 \pm 0.15 ; PTw 1.56-2.13, 1.68 \pm 0.07 ; Bl 1.20-1.60,

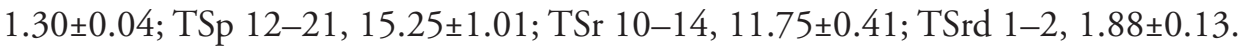

Description of female paratype. Specimen preparation and condition. Female collected live from burrow, preserved in same manner as male holotype. Genital plate removed, cleared in trypsin, stored in microvial with specimen. Color. Carapace dark reddish gray 2.5YR 3/1; legs, chelicerae, dark reddish brown 2.5YR 3/4. Abdomen reddish black dorsally 2.5YR 2.5/1 faint dusky bands dorsally; ventrum, spinnerets pale yellow (figs 10, 11). Cephalothorax. Carapace 7.36 long, 6.38 wide, generally glabrous, few thin setae, pars cephalica elevated. Fringe lacks setae. Foveal groove deep, slightly procurved. Eye group slightly elevated on very low mound. AER slightly procurved, PER slightly recurved. PME-AME subequal in diameter. Sternum widest at coxae II/III, moderately setose, STRl 4.60, STRw 4.08. Three pairs of sternal sigilla anterior pairs moderate size, oval, positioned marginally, posterior pair larger, irregularly shaped, nearly contiguous. Chelicerae anterior tooth row armed with 10 teeth with single posterior margin denticle row. Palpal endites with 47 cuspules concentrated at the inner promargin posterior heel; labium with 5 cuspules, LBw 1.46, LBl 0.97. Rastellum consist of 10 very stout spines positioned on distinct mound. Abdomen. Moderately setose, posterior median spinnerets reduced in size. Walking legs. Anterior two pairs noticeably more slender than posterior pairs. Leg I 16.39 long. Tarsus I with single staggered row of 10 trichobothria. Legs I, II with moderately heavy scopulae on tarsi, metatarsi. PT3s 14, TB3s 9. Rudimentary preening comb on retrolateral distal 
surface, tarsus - metatarsus joint metatarsus III, IV. Spermathecae. Two simple spermathecal bulbs, moderately elongate neck, arranged on low subtriangular base (fig. 9).

Variation. Females known only from three specimens.

Distribution and natural history. Known from central Alabama, counties of Choctaw, Lee, Macon, and Montgomery, and the piedmont region of Georgia, Putnam County (Map 1). The type locality comprises primarily young second growth mixed deciduous forest located at the transition from the Piedmont to Coastal Plan physiographic region. The population known from the additional material in western Alabama is located in Coastal Plain Province. Specimens were found to be presumably syntopic with Cyclocosmia, Antrodiaetus, Ummidia, and possibly $M$. torreya (collected from the region). Male specimens were collected from swimming pools and wandering on warm, damp mornings during the months of December and January. Females were collected from 6-8 cm deep burrow, some with below-ground side chambers with a trapdoor.

Genbank accession numbers. JQ708212-JQ708215

\section{Acknowledgements}

This project was supported by NSF grant DEB 0315160 and Auburn University. We are grateful to Dr. David Held for access to his property and specimens from his swimming pool. Rebecca Godwin assisted in taking measurements. Les Goertzen suggested the specific epithet tigris.

\section{References}

Atkinson GF (1886) Descriptions of some new trap-door spiders; their nests and food habits. Entomologica Americana 2: 109-137. doi: 10.1371/journal.pone.0012744

Bailey AL, Brewer MS, Hendrixson BE, Bond JE (2010) Phylogeny and classification of the trapdoor spider genus Myrmekiaphila: an integrative approach to evaluating taxonomic hypotheses. PLoS ONE 5(9): 1-15.

Bond JE (2004) Systematics of the Californian euctenizine spider genus Apomastus (Araneae: Mygalomorphae: Cyrtaucheniidae): the relationship between molecular and morphological taxonomy. Invertebrate Systematics 18: 361-376. doi: 10.1071/IS04008

Bond JE, Platnick NI (2007) A taxonomic review of the trapdoor spider genus Myrmekiaphila (Araneae, Mygalomorphae, Cyrtaucheniidae). American Museum Novitates 3596: 1-30. doi: 10.1206/0003-0082(2007)3596[1:ATROTT]2.0.CO;2

Bond JE, Hedin MC (2006) A total evidence assessment of the phylogeny of the diverse North American trapdoor spider subfamily Euctenizinae (Araneae, Mygalomorphae, Cyrtaucheniidae). Molecular Phylogenetics and Evolution 41: 70-85. doi: 10.1016/j. ympev.2006.04.026

Bond JE, Stockman AK (2008) An Integrative Method for Delimiting Cohesion Species: Finding the Population-Species Interface in a Group of Californian Trapdoor Spiders with Ex- 
treme Genetic Divergence and Geographic Structuring. Systematic Biology 57: 628-646. doi: 10.1080/10635150802302443

Funk D, Omland K (2003) Species-level paraphyly and polyphyly: Frequency, causes, and consequences, with insights from animal mitochondrial DNA. Annual Review of Ecology, Evolution and Systematics 34: 397-423. doi: 10.1146/annurev.ecolsys.34.011802.132421 Gertsch WJ, Wallace HK (1936) Notes on new and rare American mygalomorph spiders. American Museum Novitates 884: 1-25.

Hedin M, Bond JE (2006) Molecular phylogenetics of the spider infraorder Mygalomorphae using nuclear rRNA genes (18S and 28S): Conflict and agreement with the current system of classification. Molecular Phylogenetics and Evolution 41: 454-471. doi: 10.1016/j. ympev.2006.05.017

Hendrixson BE, Bond JE (2007) Molecular phylogeny and biogeography of an ancient Holarctic lineage of mygalomorph spiders (Araneae: Antrodiaetidae: Antrodiaetus). Molecular Phylogenetics and Evolution 42: 738-755. doi: 10.1016/j.ympev.2006.09.010

Huelsenbeck JP, Ronquist F (2001) MRBAYES: Bayesian inference of phylogenetic trees. Bioinformatics 17: 754-755. doi: 10.1093/bioinformatics/17.8.754

Maddison WP, Maddison DR (2009) Mesquite: a modular system for evolutionary analysis. Version 2.7 ed. doi: 10.1093/bioinformatics/btg180

Ronquist F, Huelsenbeck JP (2003) MrBayes 3: Bayesian phylogenetic inference under mixed models. Bioinformatics 19: 1572-1574.

Simon C, Frati F, Beckenbach A, Crespi B, Liu H, Paul F (1994) Evolution, Weighting, and Phylogenetic Utility of Mitochondrial Gene-Sequences and a Compilation of Conserved Polymerase Chain-Reaction Primers. Annals of the Entomological Society of America 87: 651-701.

Stamatakis A (2006) RAxML-VI-HPC: Maximum Likelihood-based Phylogenetic Analyses with Thousands of Taxa and Mixed Models. Bioinformatics 22(21): 2688-2690. doi: 10.1093/bioinformatics/btl446

Stockman AK, Bond JE (2008) A taxonomic review of the trapdoor spider genus Promyrmekiaphila Schenkel (Araneae, Mygalomorphae, Cyrtaucheniidae, Euctenizinae). Zootaxa 1823: 25-41.

Templeton AR (1998) Species and speciation: geography, population structure, ecology, and gene trees. In: Howard DJ, Berlocher SH (Eds) Endless Forms: Species and Speciation. Oxford University Press, New York, 32-43. 


\section{Appendix I}

Locality data for Myrmekiaphila tigris.

Explanation note: Locality data (CSV format) for Myrmekiaphila tigris specimens (doi: 10.3897/zookeys.190.3011.app1). File format: Microsoft Excel comma delimited.

Copyright notice: This dataset is made available under the Open Database License (http://opendatacommons.org/licenses/odbl/1.0/). The Open Database License $(\mathrm{ODbL})$ is a license agreement intended to allow users to freely share, modify, and use this Dataset while maintaining this same freedom for others, provided that the original source and author(s) are credited.

Citation: Bond JE, Hamilton CA, Garrison NL, Ray CH (2012) Phylogenetic reconsideration of Myrmekiaphila systematics with a description of the new trapdoor spider species Myrmekiaphila tigris (Araneae, Mygalomorphae, Cyrtaucheniidae, Euctenizinae) from Auburn, Alabama. ZooKeys 190: 95-109. doi: 10.3897/zookeys.190.3011.app1 
